\title{
Tumor Response to Irinotecan is Associated with IL-10 Expression Level in Metastatic Colorectal Cancer-Results from mCRC Biomarker Study
}

This article was published in the following Dove Press journal: OncoTargets and Therapy

\author{
Jinjia Chang $\mathbb{I D}^{1,2, *}$ \\ Wen Zhang ${ }^{1,2, *}$ \\ Guangyi Lin ${ }^{1,3, *}$ \\ Duo Tong ${ }^{1,2}$ \\ Dan Zhu ${ }^{1,2}$ \\ Jing Zhaol,2 \\ Qihe $\mathrm{Yu}^{1,2}$ \\ Dan Huang ${ }^{1,4}$ \\ Wenhua $\mathrm{Li}^{1,2}$
}

'Department of Medical Oncology, Fudan University Shanghai Cancer Center, Shanghai, 200032, People's Republic of China; ${ }^{2}$ Department of Oncology, Shanghai Medical College, Fudan University, Shanghai 200032, People's Republic of China; ${ }^{3}$ Shanghai Medical College, Fudan University, Shanghai 200032, People's Republic of China; ${ }^{4}$ Department of Pathology, Fudan University Shanghai Cancer Center. Shanghai 200032, People's Republic of China

*These authors contributed equally to this work

Correspondence: Wenhua Li Department of Medical Oncology, Fudan University, Shanghai Cancer Center, Shanghai, People's Republic of China Tel +86-2I-64I75590

Fax +86-2I-64I 70366

Email whliiris@hotmail.com
Purpose: Metastatic colorectal cancer $(\mathrm{mCRC})$ is a leading cause of cancer-related death. Resistance to chemotherapy is the main reason for the failure of the treatment of mCRC. IL10 has been reported to decrease after surgery and increase after mCRC reoccurrence. The role of IL-10 in chemotherapy drug resistance of mCRC is not well elucidated.

Patients and Methods: The retrospective study recruited $264 \mathrm{mCRC}$ patients between January 2012 and December 2016 (NCT03532711). All the enrolled patients received an oxaliplatin-containing or irinotecan-containing regimen. The expression level of IL-10 in 232 patients' plasma and 68 patients' tumor tissue was examined. The relationships between IL10 and clinicopathological characteristics were analyzed. Kaplan-Meier method and Cox regression were used to evaluate the prognostic impact of IL-10.

Results: The median concentration of IL-10 was $7.60 \mathrm{pg} / \mathrm{mL}$ before treatment and $11.08 \mathrm{pg} /$ $\mathrm{mL}$ after treatment, which suggested that IL-10 level was significantly increased by treatment with a chemotherapeutic regimen $(\mathrm{p}=0.000)$. By utilizing univariate and multivariate Cox proportional hazard analyses, we found that low IL-10 level in plasma was significantly associated with improved overall survival (OS) of mCRC patients treated with irinotecancontaining regimen-with optimal cutoff value of $5.525 \mathrm{pg} / \mathrm{mL}$, respectively $(\mathrm{p}=0.002)$. In addition, the low IL-10 expression level in tumor tissue was significantly associated with the improved OS for the irinotecan-containing regimen $(\mathrm{p}=0.023)$.

Conclusion: Our study demonstrated that IL-10 could act as a prognostic biomarker for mCRC patients undergoing irinotecan-containing chemotherapy.

Keywords: IL-10, metastatic colorectal cancer, chemotherapy, biomarker

\section{Introduction}

Colorectal cancer (CRC) is one of the leading causes of cancer-related mortality worldwide. In China, due to the low early diagnosis rate, most CRC patients were diagnosed at advanced stages. ${ }^{1,2}$ Despite recent progress in chemotherapeutic approaches, including targeted agents, the prognosis for metastatic CRC is still very poor. Therefore, strategies for improving patients' efficacy with metastatic colorectal cancer (mCRC) are urgently required for diagnosis and treatment in Chinese patients. Currently, chemotherapy remains the standard treatment for first- and second-line management of $\mathrm{mCRC}$. Both oxaliplatin-based and irinotecan-based chemotherapy regimens are two active choices, and either can be alternated in sequential therapy. However, chemoresistance development presents a significant challenge in the treatment and management of $\mathrm{mCRC}^{3}$ 
Previously, we conducted a clinical trial named mCRC biomarker study (NCT03532711) to explore reliable biomarkers predicting chemotherapy's drug efficacy for mCRC. By analyzing routine blood counts of mCRC patients, we demonstrated that mean platelet volume (MPV) and its related factor platelet-to-lymphocyte ratio (PLR) may act as a prognostic biomarker for mCRC. ${ }^{4}$ Herein, we aimed to identify other potential biomarkers from plasma or tumor tissue.

The association of chronic inflammation with CRC has been fully elucidated. Several inflammatory cytokines promote the development of cancer-associated with chronic inflammation. ${ }^{5,6}$ Among them, IL-10 was identified as a key promoter of carcinogenesis. However, the relationship between IL-10 and mCRC chemotherapy drug efficacy has not been reported. In the present study, we aimed to explore the effect of IL-10 expression level on chemotherapy drug effect in mCRC patients.

\section{Patients and Methods Study Description}

A retrospective observational clinical study named mCRC biomarker study was conducted as described before (NCT03532711). ${ }^{4}$ Two hundred and sixty-four mCRC patients with histopathologically confirmed mCRC who had at least one measurable lesion were enrolled in this study. According to the investigators' suggestion, the chemotherapy regimens such as FOLFIRI/XELOX/FOLFOX were chosen as first-line or second-line chemotherapy regimen. The irinotecan-containing regimen consisted of the FOLFIRI regimen (infusion and bolus 5-FU with irinotecan), and the oxaliplatin-containing regimen consisted of XELOX/FOLFOX (infusion and bolus 5-FU or oral capecitabine with oxaliplatin). An objective response rate (ORR) to chemotherapy was the primary study endpoint. The overall survival (OS) and progression-free survival (PFS) of patients were the secondary study endpoint. This study was approved by the Ethical Committees of Fudan University Shanghai Cancer Center (Ethics Number: 1203108-10). The consent was obtained from the study participants prior to study commencement. This study was conducted in accordance with the Declaration of Helsinki.

\section{Plasma IL-I0 Determination}

The concentration of IL-10 in plasma level was determined in the patients on the day before the first cycle of chemotherapy, the day before the second cycle of chemotherapy, and the day defined as progression disease evaluated by radiologic examination. Plasma levels of IL-10 were established in the sera of all the participants by ELISA, using the Quantikine kit (R\&D Systems, UK). The tests were performed following the manufacturer's instructions. Optimal density was measured at $450 \mathrm{~nm}$ using a microplate reader (bioMerieux Reader 250). The experiment was triplicated for each patient.

\section{Immunohistochemistry Analysis}

Immunohistochemical (IHC) staining was performed as described below. The tumor specimens were fixed with $10 \%$ paraformaldehyde and embedded in paraffin. The sections were incubated with IL-10 primary antibody (1:100, Abcam, USA), followed by the appropriate secondary antibody, and visualized with diaminobenzidine (DAB). Finally, the slides were counterstained with hematoxylin. For the evaluation of the IHC results, we defined low expression (immunohistochemistry score 0 or 1 ) and high expression (immunohistochemistry score 2).

\section{Statistical Analysis}

The efficacy of treatment was evaluated according to the RECIST (response evaluation criteria in solid tumors) 1.0 criteria. Progression-free survival (PFS) was defined as the interval between initial treatment and the first documentation of disease progression or death. OS was calculated as the time from initial treatment to death. The differences between-group were assessed using the Student's $t$-test. The optimum cut-off value of IL-10 was selected by using the Receiver-operating characteristics (ROC) curve. A Kaplan-Meier survival analysis was performed a $\log$ rank test to describe the analysis of survival curves. The Cox multivariate proportional hazards regression model was used to determine the independent risk factors that influence OS. P value $<0.05$ was regarded as significant. Statistical analyses were conducted using SPSS Statistics version 22.0.

\section{Results}

A total of 264 patients were enrolled in the mCRC biomarker study. Blood samples from 32 patients were not obtained; therefore, a total of 232 patients were analyzed in the current study. We measured IL-10 level in plasma samples at two-time points: before and after one treatment cycle. The median concentration of IL-10 was $7.60 \mathrm{pg} / \mathrm{mL}$ before treatment and $11.08 \mathrm{pg} / \mathrm{mL}$ after treatment, which 
suggested that IL-10 level was significantly increased by treatment with a chemotherapeutic regimen $(p=0.000)$.

The optimal cut-off value of baseline IL-10 level was $5.525 \mathrm{pg} / \mathrm{mL}$ by using ROC curve analysis (Figure 1,). Our results showed that IL-10 with $5.525 \mathrm{pg} / \mathrm{mL}$ contributed the highest prognostic value, with a sensitivity of 0.515 and a specificity of 0.38 (AUC $=0.446,95 \% \mathrm{CI}: 0.366$ $0.526, \mathrm{p}=0.192)$. Therefore, patients were classified into two independent groups: patients with IL-10 $\leq 5.525 \mathrm{pg} /$
$\mathrm{mL}(\mathrm{n}=111,47.8 \%)$ and the patients with IL-10 $>5.525$ $\mathrm{pg} / \mathrm{mL}(\mathrm{n}=121,52.2 \%)$.

The relationship between IL-10 level and clinical characteristics was shown in Table 1. Our result showed the factors including age, gender, primary tumor sites, $R A S$ status, metastases organs (liver or lung), treatment regimens (irinotecan-containing regimen or oxaliplatincontaining regimen), and drug efficacy have no difference between the two groups. The ORR (objective response

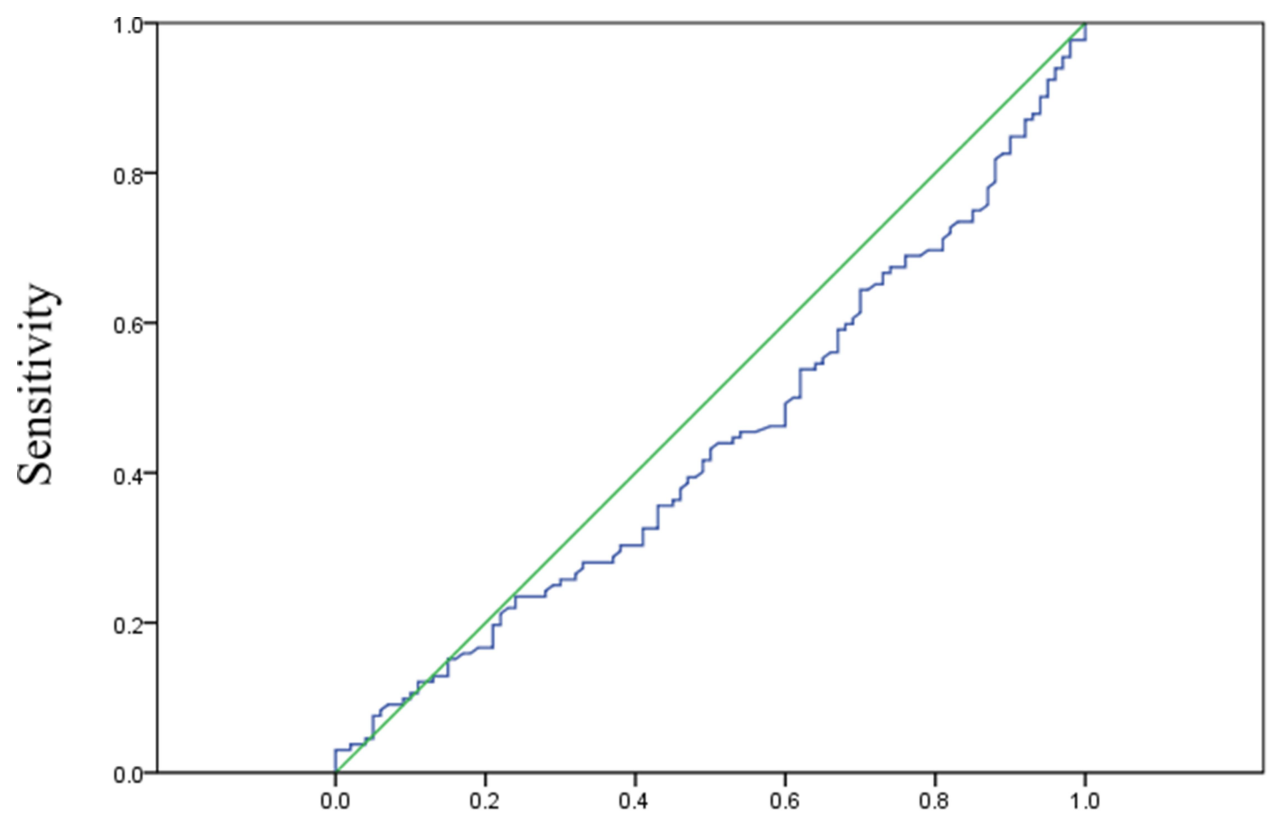

1-Sensitivity

Figure I The ROC curve determines the optimal cut-off value of IL-I0.

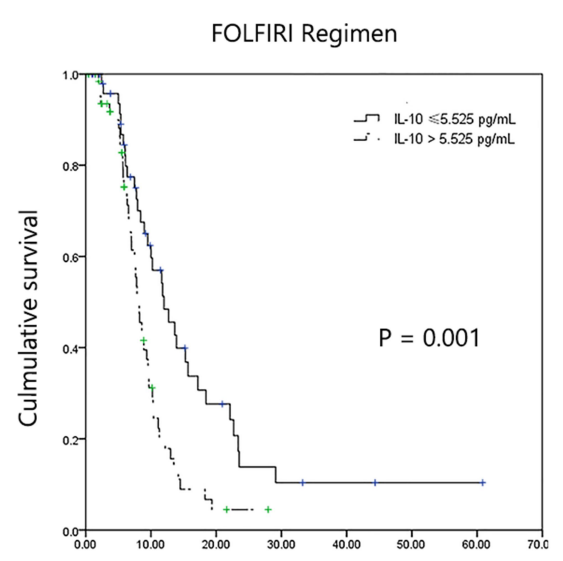

Progression free survival (months)

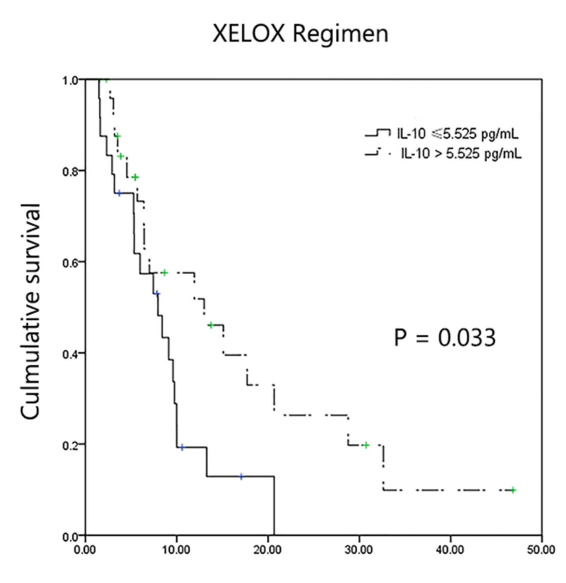

Progression free survival (months)

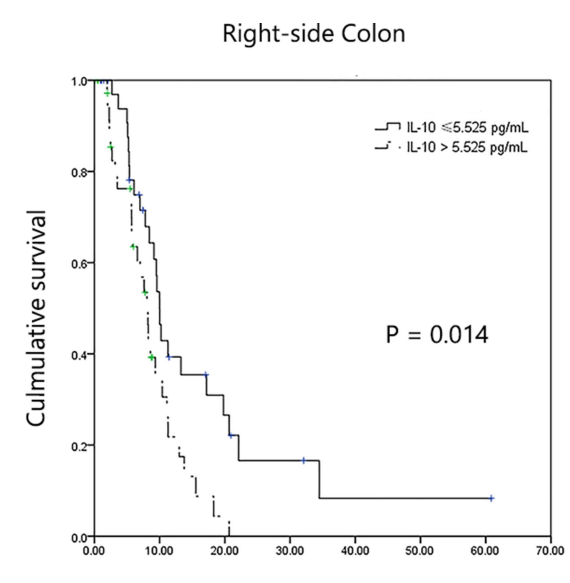

Progression free survival (months)

Figure 2 Influence of IL- 10 levels in plasma on progression-free survival by Kaplan-Meier analyses. Log-rank analysis was used to determine the statistical significance of the Kaplan-Meier survival curve $(P<0.05)$. 
Table I Baseline Characteristics of Patients with mCRC According to IL-10 Levels

\begin{tabular}{|c|c|c|c|c|}
\hline Variables & $\begin{array}{l}\text { Total } \\
\text { n (\%) }\end{array}$ & $\begin{array}{l}\mathrm{IL}-10 \leq 5.525 \\
\mathrm{pg} / \mathrm{mL}\end{array}$ & $\begin{array}{l}\text { IL- } 10>5.525 \\
\mathrm{pg} / \mathrm{mL}\end{array}$ & $P$ value \\
\hline $\begin{array}{l}\text { Age (years) } \\
\quad \leq 60 \\
>60\end{array}$ & $\begin{array}{l}109 \\
123\end{array}$ & $\begin{array}{l}51 \text { ( (46.8\%) } \\
60(48.8 \%)\end{array}$ & $\begin{array}{l}58(53.2 \%) \\
63(51.2 \%)\end{array}$ & 0.762 \\
\hline $\begin{array}{l}\text { Gender } \\
\text { Male } \\
\text { Female }\end{array}$ & $\begin{array}{l}137 \\
95\end{array}$ & $\begin{array}{l}65(47.4 \%) \\
46(48.4 \%)\end{array}$ & $\begin{array}{l}72(52.6 \%) \\
49(51.6 \%)\end{array}$ & 0.884 \\
\hline $\begin{array}{l}\text { Location } \\
\text { Colon-Left } \\
\text { Colon-Right } \\
\text { Rectum }\end{array}$ & $\begin{array}{l}74 \\
74 \\
84\end{array}$ & $\begin{array}{l}31(41.9 \%) \\
36(48.6 \%) \\
44(52.4 \%)\end{array}$ & $\begin{array}{l}43(58.1 \%) \\
38(51.4 \%) \\
40(47.6 \%)\end{array}$ & 0.414 \\
\hline $\begin{array}{l}\text { Ras status } \\
\text { Wild-type } \\
\text { Mutant-type }\end{array}$ & $\begin{array}{l}9 \\
28\end{array}$ & $\begin{array}{l}5(55.6 \%) \\
12(42.9 \%)\end{array}$ & $\begin{array}{l}4(44.4 \%) \\
16(57.1 \%)\end{array}$ & 0.703 \\
\hline $\begin{array}{l}\text { Liver metastases } \\
\text { No } \\
\text { Yes }\end{array}$ & $\begin{array}{l}91 \\
141\end{array}$ & $\begin{array}{l}45(49.5 \%) \\
66(46.8 \%)\end{array}$ & $\begin{array}{l}46(50.5 \%) \\
75(53.2 \%)\end{array}$ & 0.694 \\
\hline $\begin{array}{l}\text { Lung metastases } \\
\qquad \text { No } \\
\text { Yes }\end{array}$ & $\begin{array}{l}149 \\
83\end{array}$ & $\begin{array}{l}69(46.3 \%) \\
42(50.6 \%)\end{array}$ & $\begin{array}{l}80(53.7 \%) \\
41(49.4 \%)\end{array}$ & 0.53 \\
\hline $\begin{array}{l}\text { Regimen } \\
\text { XELOX } \\
\text { FOLFOX } \\
\text { FOLFIRI }\end{array}$ & $\begin{array}{l}50 \\
62 \\
120\end{array}$ & $\begin{array}{l}24(48 \%) \\
33(53.2 \%) \\
54(45 \%)\end{array}$ & $\begin{array}{l}26(52 \%) \\
29(46.8 \%) \\
66(55 \%)\end{array}$ & 0.574 \\
\hline $\begin{array}{l}\text { Regimen } \\
\text { Irinotecan- } \\
\text { containing } \\
\text { Oxaliplatin- } \\
\text { containing }\end{array}$ & $\begin{array}{l}120 \\
112\end{array}$ & $\begin{array}{l}54(45 \%) \\
57(50.9 \%)\end{array}$ & $\begin{array}{l}66(55 \%) \\
55(49.1 \%)\end{array}$ & 0.369 \\
\hline $\begin{array}{l}\text { Efficacy } \\
\text { CR+PR } \\
\text { SD+PD } \\
\text { NK }\end{array}$ & $\begin{array}{l}72 \\
140 \\
20\end{array}$ & $\begin{array}{l}36(50 \%) \\
65(46.4 \%)\end{array}$ & $\begin{array}{l}36(50 \%) \\
75 \text { (53.6\%) }\end{array}$ & 0.622 \\
\hline
\end{tabular}

Abbreviations: NK, not known; CR, complete response; SD, stable disease; PD, progression disease.

rate) in the two groups was $46.4 \%$ and $53.6 \%(\mathrm{p}=0.622)$, respectively.

Next, we used Kaplan-Meier method to describe the analysis of survival curves. As shown in Table 2, for the whole population, patients with high IL-10 expression level showed no significant difference in PFS or OS compared with patients with low IL-10 expression level (PFS: $9.87 \pm 0.497$ months vs $8.27 \pm 0.601$ months, $p=0.264$; OS: $20.97 \pm 3.78$ months vs $20.2 \pm 3.137$ months, $p=0.488)$. The subgroup analysis showed that low IL-10 level was associated with longer PFS for patients treated with the irinotecan-containing regimen than those with high IL-10 level ( $12 \pm 3.75$ vs $7.9 \pm 1.06$ months, $p=0.001)$. However, for patients treated with oxaliplatin-containing regimen (XELOX), low IL-10 level was associated with shorter PFS than those with high IL-10 level $(7.93 \pm 3.56$ vs 13 \pm 9.99 months, $p=0.033$ ). Meanwhile, for the patients with primary tumor located on the right-side colon, low IL-10 level was associated with longer PFS than those with high IL-10 level ( $10 \pm 0.93$ vs $8.07 \pm 1.55$ months, $p=0.014)$. Notably, no marked differences were identified in the OS between the two groups (see Figure 2).

In addition, we performed univariate and multivariate Cox proportional-hazards regression analyses in 120 patients who received an irinotecan-containing regimen. As shown in Table 3, univariate analysis showed that lower IL-10 level was significantly associated with improved PFS $(p=0.002)$. Variables with a $p$ value of less than 0.1 were then included in the multivariate model. As a result, the only gender was proved to be an independent factor for PFS (Table 4).

We next investigated the relationship between the IL10 expression in tumor tissue and patient prognosis. We collected 68 tissue specimens and performed IHC analysis (Figure 3). As shown in Table 5 and Figure 4, Kaplan-Meier survival analysis showed that patients with high IL-10 expression had significantly poor OS compared with low expression $(25.33 \pm 18.89$ vs 18.37 \pm 4.66 months, $\mathrm{p}=0.035$ ).

Subgroup analysis revealed that patients receiving irinotecan-containing regimen had low expression level of IL-10 and was significantly associated with better OS $(34.33 \pm 17.84$ vs $14.1 \pm 11.43$ months, $\mathrm{p}=0.028)$, while no significant OS advantage was observed in patients receiving oxaliplatin-containing regimen $(17.033 \pm 2.2$ vs $21.167 \pm 2.054$ months, $p=0.483$, see Figure 4).

\section{Discussion}

IL-10 is known as an important immunoregulatory cytokine, plays multiple biological roles. It has been well documented in inflammatory diseases due to its anti-inflammatory and immunoregulation properties. ${ }^{7,8}$ However, the role of IL-10 in tumorigenesis remains not well elucidated. Previous studies indicated that IL-10 could promote tumorigenesis and systemic tumor immune suppression. ${ }^{9}{ }^{910}$ Conversely, IL-10 itself has been reported to have potent immune-dependent anti-tumor effects. ${ }^{11,12}$ To the best of our knowledge, IL-10 and its impact on chemotherapy efficacy in mCRC has not been investigated yet. In the current study, we aimed to 
Table 2 Association of IL-10 with the Survival Data According to the Chemotherapeutic Regimen and Primary Tumor Location

\begin{tabular}{|c|c|c|c|c|}
\hline & & IL- $10 \leq 5.525$ & IL- $\mid 0>5.525$ & $P$ value \\
\hline PFS (mons) & $\begin{array}{l}\text { Regimen } \\
\text { FOLFIRI }(n=120) \\
\text { FOLFOX }(n=62) \\
\text { XELOX }(n=50) \\
\text { Primary tumor location } \\
\text { Colon-Left }(n=74) \\
\text { Colon-Right }(n=74) \\
\text { Rectum }(n=84)\end{array}$ & $\begin{array}{l}9.87(8.895-10.845)(n=111) \\
12(8.25-15.75)(n=54) \\
9.03(6.474-11.586)(n=33) \\
7.93(4.37 I-11.489)(n=24) \\
9.87(5.562-14.178)(n=31) \\
10(9.074-10.926)(n=36) \\
9.03(6.820-11.240)(n=44)\end{array}$ & $\begin{array}{l}8.27(7.092-9.448)(n=121) \\
7.9(6.837-8.963)(n=66) \\
8.7(4.458-12.942)(n=29) \\
13(3.011-22.989)(n=26) \\
8.27(7.150-9.390)(n=43) \\
8.07(6.518-9.622)(n=38) \\
10.23(5.050-15.405)(n=40)\end{array}$ & $\begin{array}{l}0.264 \\
0.001 \\
0.998 \\
0.033 \\
\\
0.94 \\
0.014 \\
0.683\end{array}$ \\
\hline OS (mons) & $\begin{array}{l}\text { Regimen } \\
\text { FOLFIRI }(n=120) \\
\text { FOLFOX }(n=62) \\
\text { XELOX }(n=50) \\
\text { Primary tumor location } \\
\text { Colon-Left }(n=74) \\
\text { Colon-Right }(n=74) \\
\text { Rectum }(n=84)\end{array}$ & $\begin{array}{l}20.97(\mid 9.080-22.860)(n=|I|) \\
22.37(|2.879-31.86|)(n=54) \\
21.7(\mid 4.974-28.426)(n=33) \\
14.63(\mid 3.099-16.16 I) \quad(n=24) \\
19.9(\mid 5.684-24.116)(n=3 \mid) \\
20.67(\mid 15.185-26.155) \quad(n=36) \\
25.47(\mid 7.738-33.302) \quad(n=44)\end{array}$ & $\begin{array}{l}20.2(17.063-23.337)(n=121) \\
20.5(15.420-25.580)(n=66) \\
21.47(13.264-29.676)(n=29) \\
19.1(14.697-23.503) \quad(n=26) \\
20.2(15.076-25.324) \quad(n=43) \\
16.4(12.589-20.211) \quad(n=38) \\
26.93(7.952-45.908) \quad(n=40)\end{array}$ & $\begin{array}{l}0.488 \\
0.122 \\
0.662 \\
0.112 \\
0.828 \\
0.208 \\
0.688\end{array}$ \\
\hline
\end{tabular}

Table 3 Results of Univariate Analysis of Progression-Free Survival in Patients with mCRC Receiving FOLFIRI Regimen

\begin{tabular}{|l|l|l|l|}
\hline Variables & Hazard Ratio & $\mathbf{9 5 \% ~ C l}$ & P-value \\
\hline Age (years) $(\geq 60$ versus $<60)$ & 1.256 & $0.79-1.996$ & 0.335 \\
Gender & 1.567 & $0.993-2.475$ & 0.054 \\
IL-I0 $(\leq 5.525$ versus $>5.525)$ & 2.112 & $1.329-3.355$ & 0.002 \\
Primary tumor location & 1.156 & $0.875-1.527$ & 0.307 \\
Liver metastasis & 0.914 & $0.588-1.421$ & 0.689 \\
Lung metastasis & 0.896 & $0.57-1.408$ & 0.634 \\
Efficacy & 1.079 & $0.63-1.849$ & 0.782 \\
\hline
\end{tabular}

Table 4 Results of Multivariate Analysis of Progression-Free Survival in Patients with mCRC Receiving FOLFIRI Regimen

\begin{tabular}{|l|l|l|l|}
\hline Variables & $\begin{array}{l}\text { Hazard } \\
\text { Ratio }\end{array}$ & $\mathbf{9 5 \%} \mathbf{~ C l}$ & P-value \\
\hline $\begin{array}{l}\text { Gender } \\
\text { IL-IO ( } \leq 5.525 \text { versus } \\
>5.525)\end{array}$ & 2.037 & $1.277-3.248$ & 0.003 \\
\hline
\end{tabular}

identify the role of IL-10 in predicting first-line chemotherapy drug sensitivity in mCRC patients.

Previously, a prospective clinical study was conducted to identify the promising biomarkers from chemotherapy in mCRC. The expression of IL-10 in plasma samples from 234 mCRC patients was examined. Our results showed that compared with the baseline, IL-10 was significantly increased in patient plasma after chemotherapy, both with oxaliplatin- containing and irinotecan-containing regimen. Interestingly, IL-10 was significantly decreased after surgery and increased when the tumor recurred in operable CRC. ${ }^{13,14}$ It may be a different situation in early-stage CRC. Moreover, our results showed that the group of mCRC patients with low IL-10 level had better PFS than those with high IL-10 level $(p=0.001)$. Notably, these patients refer to patients treated with irinotecancontaining regimen but not oxaliplatin-containing regimen. More importantly, IL-10 expression in tumor tissue also demonstrated that low expression level of IL-10 was significantly associated with better OS $(p=0.035)$, again in patients treated with irinotecan-containing regimen $(\mathrm{p}=0.023)$; however, not in the oxaliplatin-containing regimen $(\mathrm{p}=0.483)$.

Irinotecan, a water-soluble and semisynthetic derivative of camptothecin, is one of the widely used first- and second-line chemotherapeutics drugs for treating patients with mCRC. Several factors may reduce the sensitivity of irinotecan drug efficacy, including downregulation of topoisomerase-I, decreased activity of the metabolic enzyme and increased drug transporters to the membrane. ${ }^{15-17}$ Previously, we reported that $\mathrm{mCRC}$ patients bearing single nucleotide polymorphisms in MTHFR and ABCG2 might benefit from irinotecan-containing regimen. ${ }^{18}$ Herein, we first demonstrated that IL-10 expression level was significantly associated with irinotecan therapeutic efficacy. Our results suggested that IL-10 could serve as a promising biomarker for evaluating the chemotherapeutic regimen choose for patients with mCRC. 
A

B

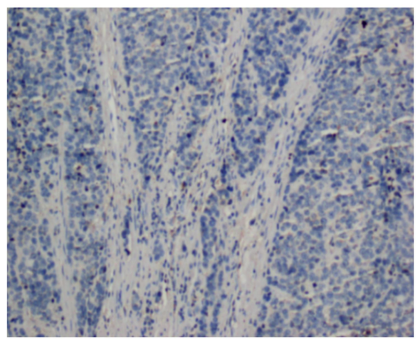

Negative (Score 0)

C
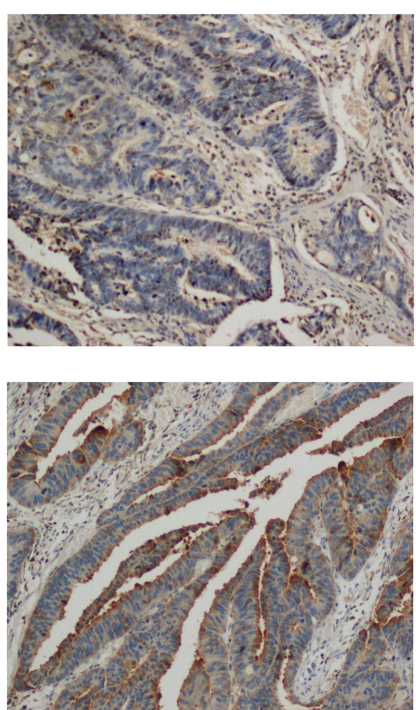

A

Overall Population

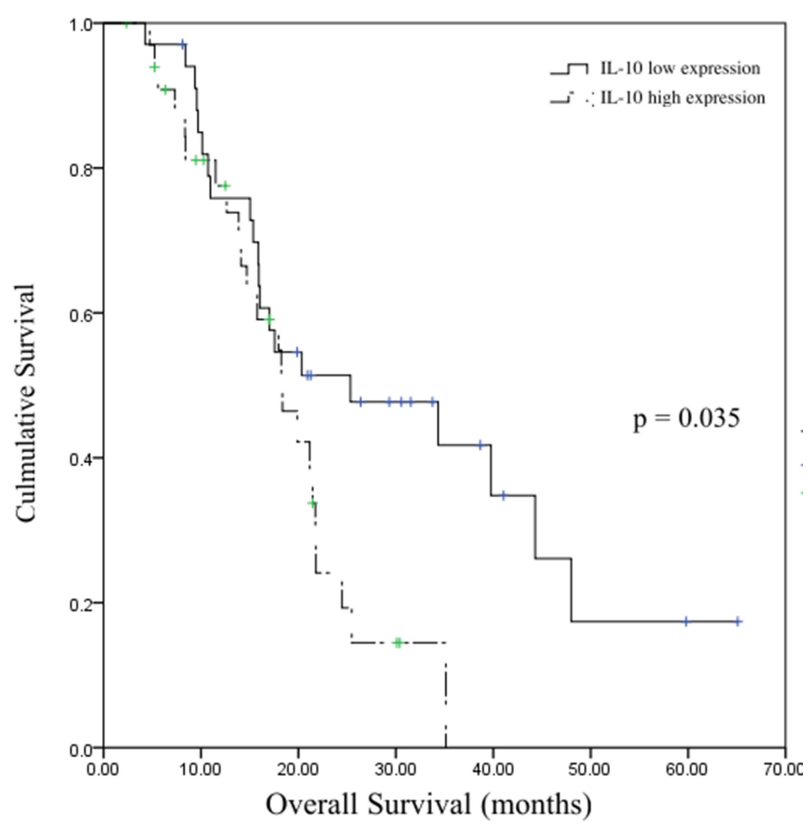

Strong positive(Score 2)

B

FOLFIRI Regimen

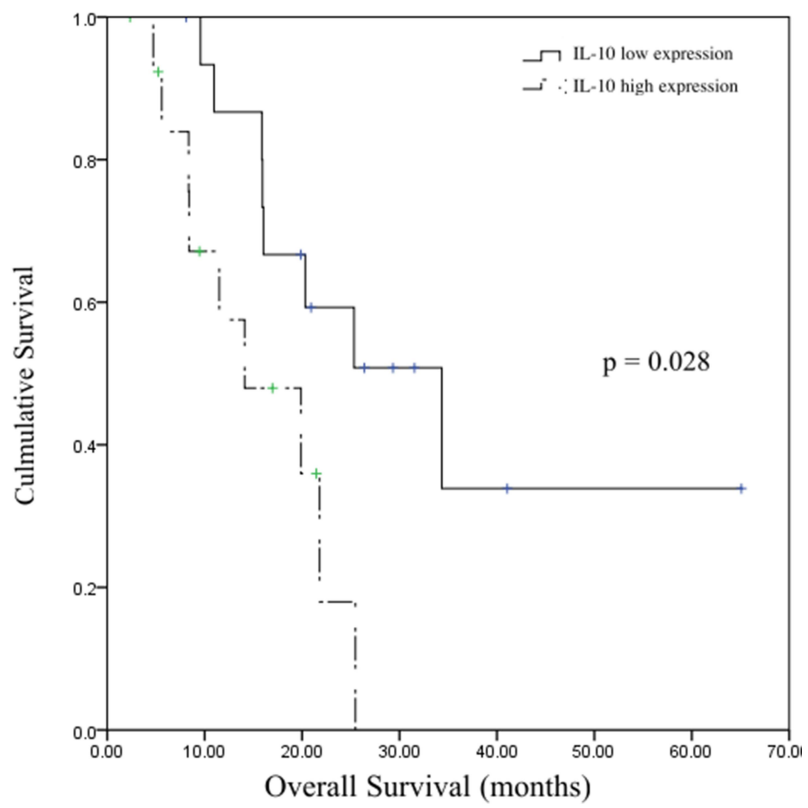

Figure 4 Influence of IL-10 levels in tumor tissue on the progression of overall survival by Kaplan-Meier analyses. Log-rank analysis was used to determine the statistical significance of the Kaplan-Meier survival curve $(P<0.05)$. (A) Patients with high IL-10 tissue expression level had significant shorter OS than those with low IL-10 expression level $(p=0.035)$. (B) Subgroup analysis showed that in irinotecan containing regimen treated patients, high IL-10 tissue expression level had significant shorter OS than those with low IL-10 expression level $(p=0.028)$.

combine anti-IL-10 and irinotecan for the treatment of the patient with mCRC. As known, oxaliplatin and irinotecan are alternative regimens for metastatic colorectal cancer in the 
first-line setting, with similar overall efficacy. In order to distinguish which patients could benefit more from irinotecan-based regimen, our research has provided a simple and convenient choice, which is helpful to solve practical clinical problems.

The current study has some limitations. We did not discuss the underlying mechanism of IL-10 mediated irinotecan drug resistance. Besides, the findings in the plasma-based sample should be verified in a larger size of tumor tissue. Further studies are needed to discover the possibility of combined treatment of IL-10 and irinotecan in $\mathrm{mCRC}$.

\section{Conclusion}

In conclusion, IL-10 was proved to act as a prognostic biomarker for mCRC patients undergoing irinotecancontaining chemotherapy. We believed that the current study's findings provided a valuable reference for the firstline chemotherapy for mCRC patients.

\section{Ethics Approval and Informed Consent}

This study was approved by the Ethical Committees of the Fudan University Shanghai Cancer Center (Ethics Number: 1203108-10).

\section{Acknowledgments}

The abstract of this paper was presented at ESMO 2020 as a poster presentation with interim findings. The poster's abstract was published in "Poster Abstracts" in the Journal of Annals of Oncology (https://doi.org/10.1016/j.annonc.2020. $\underline{08.567)}$.

\section{Funding}

This study was supported by the National Natural Science Foundation of China (NSFC81602081).

\section{Disclosure}

The authors report no conflicts of interest in this work.

\section{References}

1. Cheng AL, Li J, Vaid AK, et al. Adaptation of international guidelines for metastatic colorectal cancer: an Asian consensus. Clin Colorectal Cancer. 2014;13(3):145-155. doi:10.1016/j.clcc.2014.06.004

2. Torre LA, Bray F, Siegel RL, Ferlay J, Lortet-Tieulent J, Jemal A. Global cancer statistics, 2012. CA Cancer J Clin. 2015;65(2):87-108. doi:10.3322/caac. 21262
3. Ciombor KK, Wu C, Goldberg RM. Recent therapeutic advances in the treatment of colorectal cancer. Annu Rev Med. 2015;66:83-95. doi:10.1146/annurev-med-051513-102539

4. Chang J, Lin G, Ye M, et al. Decreased mean platelet volume predicts poor prognosis in metastatic colorectal cancer patients treated with first-line chemotherapy: results from mCRC biomarker study. $B M C$ Cancer. 2019;19(1):15. doi:10.1186/s12885-018-5252-2

5. Foersch S, Waldner MJ, Neurath MF. Colitis and colorectal cancer. Dig Dis. 2012;30(5):469-476. doi:10.1159/000341692

6. Kim J, Lee J, Oh JH, et al. Plasma inflammatory biomarkers and modifiable lifestyle factors associated with colorectal cancer risk. Clin Nutr. 2019.

7. Mannino MH, Zhu Z, Xiao H, Bai Q, Wakefield MR, Fang Y. The paradoxical role of IL-10 in immunity and cancer. Cancer Lett. 2015;367(2):103-107. doi:10.1016/j.canlet.2015.07.009

8. Mocellin S, Panelli MC, Wang E, Nagorsen D, Marincola FM. The dual role of IL-10. Trends Immunol. 2003;24(1):36-43. doi:10.1016/ S1471-4906(02)00009-1

9. Sarris AH, Kliche KO, Pethambaram P, et al. Interleukin-10 levels are often elevated in serum of adults with Hodgkin's disease and are associated with inferior failure-free survival. Ann Oncol. 1999;10 (4):433-440. doi:10.1023/A:1008301602785

10. Visco C, Vassilakopoulos TP, Kliche KO, et al. Elevated serum levels of IL-10 are associated with inferior progression-free survival in patients with Hodgkin's disease treated with radiotherapy. Leuk Lymphoma. 2004;45(10):2085-2092. doi:10.1080/10428190410001712234

11. Kaio E, Tanaka S, Oka S, et al. Clinical significance of thrombospondin-1 expression in relation to vascular endothelial growth factor and interleukin-10 expression at the deepest invasive tumor site of advanced colorectal carcinoma. Int J Oncol. 2003;23 (4):901-911.

12. Soria JC, Moon C, Kemp BL, et al. Lack of interleukin-10 expression could predict poor outcome in patients with stage I non-small cell lung cancer. Clin Cancer Res. 2003;9(5):1785-1791.

13. Galizia G, Lieto E, De Vita F, et al. Circulating levels of interleukin-10 and interleukin-6 in gastric and colon cancer patients before and after surgery: relationship with radicality and outcome. J Interferon Cytokine Res. 2002;22(4):473-482. doi:10.1089/ 10799900252952262

14. Galizia G, Orditura M, Romano C, et al. Prognostic significance of circulating IL-10 and IL-6 serum levels in colon cancer patients undergoing surgery. Clin Immunol. 2002;102(2):169-178. doi:10.1006/clim.2001.5163

15. Meisenberg C, Ashour ME, El-Shafie L, et al. Epigenetic changes in histone acetylation underpin resistance to the topoisomerase I inhibitor irinotecan. Nucleic Acids Res. 2017;45(3):1159-1176.

16. Lin X, Stenvang J, Rasmussen MH, et al. The potential role of Alu $\mathrm{Y}$ in the development of resistance to SN38 (Irinotecan) or oxaliplatin in colorectal cancer. BMC Genomics. 2015;16:404. doi:10.1186/ s12864-015-1552-y

17. Guo J, Xu S, Huang X, et al. Drug resistance in colorectal cancer cell lines is partially associated with aneuploidy status in light of profiling gene expression. J Proteome Res. 2016;15(11):4047-4059. doi:10.1021/acs.jproteome.6b00387

18. Zhao J, Li W, Zhu D, et al. Association of single nucleotide polymorphisms in MTHFR and ABCG2 with the different efficacy of first-line chemotherapy in metastatic colorectal cancer. Med Oncol. 2014;31(1):802. doi:10.1007/s12032-013-0802-6

19. Mumm JB, Oft M. Pegylated IL-10 induces cancer immunity: the surprising role of IL-10 as a potent inducer of IFN-gamma-mediated CD8(+) T cell cytotoxicity. Bioessays. 2013;35(7):623-631. doi:10.1002/bies.201300004

20. Vicari AP, Chiodoni C, Vaure C, et al. Reversal of tumor-induced dendritic cell paralysis by $\mathrm{CpG}$ immunostimulatory oligonucleotide and anti-interleukin 10 receptor antibody. J Exp Med. 2002;196 (4):541-549. doi:10.1084/jem.20020732 


\section{Publish your work in this journal}

OncoTargets and Therapy is an international, peer-reviewed, open access journal focusing on the pathological basis of all cancers, potential targets for therapy and treatment protocols employed to improve the management of cancer patients. The journal also focuses on the impact of management programs and new therapeutic

Submit your manuscript here: https://www.dovepress.com/oncotargets-and-therapy-journal agents and protocols on patient perspectives such as quality of life, adherence and satisfaction. The manuscript management system is completely online and includes a very quick and fair peer-review system, which is all easy to use. Visit http://www.dovepress.com/ testimonials.php to read real quotes from published authors. 